\title{
ИССЛЕДОВАНИЯ В ОБЛАСТИ ОПТИМИЗАЦИИ СТРУКТУРЫ АЛКАЛОИДА ФАСКАПЛИЗИН - ПЕРСПЕКТИВНОГО СОЕДИНЕНИЯ-ЛИДЕРА
}

\section{М.Е. Жидков}

Школа Естественных Наук, Дальневосточный Федеральный Университет (ДВФУ), 690922, Россия, г. Владивосток, о. Русский, п. Аякс, 10.

Среди широкого спектра вторичных метаболитов морского происхождения, известных на сегодняшний день, особое место занимает группа алкалоидов, в основе которых лежит пентациклическая система пиридо[1,2-a:3,4-b'] дииндола (1). Наиболее изученным представителем этой серии природных соединений является красный пигмент фаскаплизин (2), впервые выделенный из губки Fascaplysinopsis sp. в 1988 году [1]. Он сочетает противобактериальное, противогрибковое и противовирусное действие с антиангиогенными свойствами и цитотоксической активностью в отношении различных типов опухолевых клеток по нескольким механизмам, включая индукцию апоптоза, ингибирование клеточного цикла и др. [2-4].

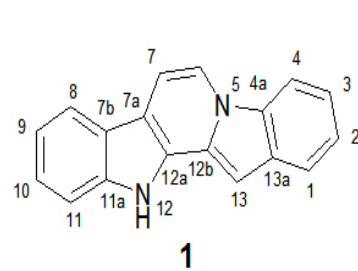

В ходе исследований были разработаны методы внедрения в структуру фаскаплизина широкого набора заместителей по различным циклам базовой структуры. Получена и изучена большая серия производных нативного алкалоида. Среди исследованных соединений выявлены перспективные соединения-лидеры, обладающие улучшенными по сравнению с родоначальным алкалоидом противоопухолевыми и антибактериальными свойствами.

\section{Литература}

[1] D. M. Roll, C. M. Ireland, J. Org. Chem. 1988, № 8, P. 3276-3278.

[2] S. B. Bharate, S. Manda, N. Mupparapu, N. Battini, R. A. Vishwakarma, Mini Rev Med Chem. 2012, 12 (7), 650-664.

[3] T. A. Johnson, L. Milan-Lobo, T. Che, M. Ferwerda, E. Lambo, N. L. McIntosh, F. Li, L. He, N. Lorig-Roach, P. Crews, J. L. Whistler, ACS Chem Neurosci. 2016, DOI: 10.1021/ acschemneuro.6b00167.

[4] Q. Sun, F. Liu, J. Sang, M. Lin, J. Ma, X. Xiao, S. Yan, C. B. Naman, N. Wang, Sh. He, X. Yan, W. Cui, H. Liang, Mar Drugs. 2019, 17(2), doi: 10.3390/md17020121. 